\title{
Spectators' negotiations of risk, masculinity and performative mobilities at the TT Races
}

Article

Accepted Version

Terry, A., Maddrell, A., Gale, T. and Arlidge, S. (2015)

Spectators' negotiations of risk, masculinity and performative mobilities at the TT Races. Mobilities, 10 (4). pp. 628-648. ISSN 17450101 doi:

https://doi.org/10.1080/17450101.2014.895175 Available at https://centaur.reading.ac.uk/75483/

It is advisable to refer to the publisher's version if you intend to cite from the work. See Guidance on citing.

To link to this article DOI: http://dx.doi.org/10.1080/17450101.2014.895175

Publisher: Taylor \& Francis

All outputs in CentAUR are protected by Intellectual Property Rights law, including copyright law. Copyright and IPR is retained by the creators or other copyright holders. Terms and conditions for use of this material are defined in the End User Agreement.

www.reading.ac.uk/centaur 
Central Archive at the University of Reading

Reading's research outputs online 


\title{
Spectators' negotiations of risk, masculinity and performative mobilities at the TT races
}

\author{
Alan Terry, Avril Maddrell , Tim Gale and Simon Arlidge \\ University of the West of England
}

\begin{abstract}
This paper explores the particular assemblage of place, event and individual identity-performances that occur each year in the Isle of Man in and through the TT (Tourist Trophy) motorcycle races. These road races are associated with a high degree of risk for the racers and the confluence of over 30,000 visitors and 10,000 motorcycles also presents potential risks for spectators and residents alike. Both motorcycling and risk-taking have been associated with particular forms of masculinity, notably hegemonic, working class and youthful masculinities. Using detailed surveys of spectators we argue that the TT races, while undoubtedly dominated by men and predicated on a cultural privileging of speed and skill, are grounded in varying combinations of determinate and reflexive attitudes to risk, reflecting the performance of a variety of gendered, 'biker' and wider identity-based positionalities. Findings also highlight a particular inter-relation of mobilities and place identity at the TT races and brings to light the highly significant and under-researched embodied, performative and emotional mobilities of spectators. The conceptual and methodological importance of a) situated research of mobiliities in specific place-temporalities; and b) wider surveys of motorcyclists to complement ethnographic studies of small cohorts are also stressed.
\end{abstract}

Key words: Isle of Man TT, masculinities, moto-mobilities, risk, road racing, spectators

\section{Introduction}

The importance of studying motorcyclists as participants in an alternative form of moto-mobility has recently been argued by Pinch and Reimer (2012) on the grounds that motorcycles are virtually absent in mobilities studies, yet represent a very different set of travelling dispositions and emotions relative to much-studied car drivers. As they point out, riding motorcycles is characterised by both a particular embodied experience of the 'here and now' (Hutch 2007) and higher risks compared to driving a car. Motorcycle mobilities have tended to be characterised as the preserve of working class heterosexual men or outlaw gangs, in part as a result of focused small cohort studies (e.g. Willis, 1978) and film and media coverage, which often results in the reiteration of simplistic stereotypes, e.g. motorcyclists as risk takers (Pinch and Reimer 2012). Motorised sub-cultures and their relation to risk and gender will be discussed in more detail below, but at this point it is important to note 
that different modes and purposes of transport and communication, result in different forms of mobility, as do different locational and social contexts, including the spatial settings or what has been described as the 'moorings' of particular mobilities (Cresswell and Merriman 2011; Hannam et al 2006). Here, we are focusing specifically on the subject positions of spectators, set within the context of the place-temporality (Wunderlich 2010) of the TT (Tourist Trophy) motorcycle races in the Isle of Man.

The spatial context is important to this study '... spaces have their own grammar which can direct or limit mobility. They produce structural or infrastructural contexts for the practising of mobility. They are agents in the production of mobilities ... [and] they are also actively produced by the act of moving' (Cresswell and Merriman 2011: 7). The TT races represent an intersection of a unique placetemporality and an assemblage of mobilities set in the context of the sub-culture or field of motorcycle road racing. The Isle of Man's wider place identity reflects its distinct political and cultural context, including its independent legislature (as a Crown Dependency outside the United Kingdom), as a historical resort for mass tourism in the Victorian and Edwardian eras (Cooper and Jackson 1989), and as a distinct geographical entity as an island located in the Irish Sea. Mobilities are particularly important in shaping the experience of islands (Vannini and Taggart 2012) but equally islands require and afford particular mobilities. As Sheller and Urry (2004: 5) note, places are 'not fixed and unchanging but depend in part upon what happens to be practised within them'. For the Isle of Man, the TT races are an important part of those practices that provide the Island with an international iconic status within motorsports, as well as generating annual visitor spending of circa f19 million (Isle of Man Treasury, 2010). For the duration of the TT festival the Island becomes a motorcycle-focused social and competitive space, shaped by its 'islandness' and its independent legislature, aspects of which are discussed below. First we outline the history and character of the TT races in order to set the scene for the following discussion.

\section{A brief account of the TT races}

'[the TT is] the Everest of motorsport and spectators share in the experience with the racers' (16, Visitor, Male, 30-44 years)

The TT races date from 1907 and the current course was inaugurated in 1911. Soon after it was established, the TT races were recognised as 'the most important sporting event on the calendar of the international motorcycling community' (Disko 2007: 3). From the outset it was seen as a test of individual and national physical-industrial strength, for both racers and motorcycle manufacturers (Vaukins 2007), with the top TT racers historically identified as embodying an ideal sporting 
masculinity (Disko 2007). Part of that ideal was a willingness to face the risks associated with, and skills required by, the course. Between 1949 and 1975, the TT was an optional part of the Motorcycle Grand Prix World Championship but, in 1976, the race lost its World Championship status due to concerns about levels of risk to racers. This inevitably marginalised the TT from the circuit-based economy of motorcycle racing, deemed as less risky. While many of today's leading TT racers combine short circuit with road racing, as motorsports commentator, Murray Walker, notes of TT competitors:

'Today everyone who competes is doing so because of their love for the sport and the thrill of taking on the greatest challenge in motor sport, fully aware of the dangers. Many of the riders have lost close friends in road racing but their passion for the event remains too great to give it up' (Walker 2010: 71).

The circuit is made up of 37.7 miles of public roads which are closed for the duration of the races and associated practice sessions. Races typically consist of four to six laps (i.e. 150 to 225 miles in total) with the fastest riders in recent years lapping the circuit at average speeds over $130 \mathrm{mph}$ and reaching speeds of $200 \mathrm{mph}$ on the straights. Although operated as a staggered time trial race to minimise collisions, the combination of its length and technical challenges have resulted in the TT being known as the ultimate challenge in motorcycle racing. This combination of risk and skill attracts extreme sport media, sponsors (such as Monster Energy), and a loyal body of spectators. Annual visitors to the TT festival number between 31,000 and 38,000 (2010-12), accompanied by over 10,000 motorcycles (Isle of Man Today, 2010). TT visitor numbers inevitably have a huge impact on the social life and movements of the near 86,000 population of the island, including the mobilities and sense of place of those residents. The focus here, however, is on those who engage as spectators at the races, whether visitor or resident, with particular reference to motorcyclist spectators. The methodologies of data collection are outlined below before links between motorcyclists, risk, gender, identity and performance are discussed.

\section{Methodologies}

A multi-method approach was deployed in this study, echoing Falconer and Kingham's (2007) study of illegal street races. Informal interviews were initially conducted in two UK 'biker cafes' in order to identify key dimensions of TT experience from those who had previously attended the races. This pilot data informed the detailed questionnaire, which provided the core of data discussed here. The questionnaire, which included closed and open questions, and was completed by 167 respondents during TT Practice Week in 2010 and Race Week in 2011. These respondents were selected randomly 
at locations where TT spectators were to be found: at various points around the course on race days and at other festival events. Eighty-one per cent of the sample comprised visitors (10 per cent international visitors) and 19 per cent island residents; two thirds were over 30 years of age; seventynine per cent identified as male and 21 per cent as female. No one self-identified as transgender and no visible ethnic minority spectators were encountered. Seventy-eight per cent of respondents were motorcycle riders. Where relevant, statistics are expressed as a percentage of those answering a given question; some questions allowed multiple responses, as reflected in the figures. Where Individual respondents are quoted below, they are identified by questionnaire number, visitor or resident status, gender and age group. The questionnaires were supplemented by stakeholder interviews, participant observation and 96 TT word association sheets were also completed by a separate random set of respondents attending TT events, rather than the races per se (see Figure 2). Of the 94 per cent who recorded their personal details, 68 per cent were male and 32 per cent female; 33 per cent were local residents and 67 per cent visitors. It is also worth noting that our own research team broadly reflected these demographics of TT spectators: three men and one woman; the latter is Manx and grew up on the Isle of Man, while the three others were visiting (for the first time); two are daily motorcycle riders, and travelled to the loM with their motorcycles.

\section{Gender, speed and risk in driving cultures}

Given the predominance of male spectators at the TT races, gendered identities are particularly salient to understanding the discursive framing of the event and the identity performance and practices at/in this time-place. The following section maps central debates on the social construction of gender and masculinities, these debates are then linked to discussions of speed and risk in wider driving cultures, including motorised sub-cultures.

Gender is a social construction, whereby social value, roles and expectations are associated with and performed by specific genders, in particular societies at a given time (Butler 1990; WGSG 1997). As with the wider notion of identity, masculinity is diverse and relational (Connell 1995) and geographers have highlighted how the production of gender is tied closely to the production of space/place (Hopkins 2007; Leyshon and Brace 2007), as well as intersecting with other identity markers/axes of difference (e.g. ethnicity, sexuality). Hence, within gender studies there has been a call for more attention to the geographical specificity of particular expressions of masculinity: 
'Masculinities ... are both temporally and geographically contingent ... It is this very contingent and unstable character that makes the process and spaces of identity production so important in both the construction of masculinities, and ... in the construction of ways of understanding masculinities' (Berg and Longhurst 2003: 352).

Masculinity, as a socially constructed attribute, functions in three key ways: as a position within a hegemonic hierarchy; as a system of gender relations and practices; and as an ideology which justifies patriarchy (Levy 2007). Connell 's (1987) concept of hegemonic masculinity identifies situated dominant ideals of manhood as power-wielding (over other men and all women), with other forms of masculinity existing in hierarchical relation to this ideal: 'complicit' (the majority of men), 'subordinate' and 'marginalized' masculinities. Significantly, hegemonic masculinity only needs to be supported by the majority of other men, rather than practised by them (Coles 2009). In this model 'complicit' men aspire to, and act out, some attributes of hegemonic masculinity, notably the subordination of women, and men who hold a 'subordinate' position within the hierarchy are those who fail to perform sufficient aspects/practices of accepted hegemonic modes of masculinity. Thus Levy (2007) summarises that 'hegemonic complicity can be measured across four dimensions: idealtype masculinity; hierarchical ranking of self and others; subordination of women; and the subordination of woman-like behaviour'. Connell's model is somewhat reductionist, especially in the light feminist work on diversity and intersectionality (see WGSG 1997) and more recent work suggests that 'multiple dominant masculinities ... operate within subfields bound by a [wider] field of masculinity', with each of those subfields accommodating multiple forms of masculinities (Coles 2009: 30). Here we are attentive to the dynamic culture of hierarchical ranking of self and others by men (Connell 1987, Levy 2007) which can produces a constant sense of surveilled masculinity (see Falconer and Kingham 2007; Evans and Wallace 2008: 485), while acknowledging the potential presence of multiple dominant masculinities. As with the typologies of masculinity above, Connell's (1987) identification of women's 'emphasized', resistant and compliant femininities are far from allencompassing, but have nonetheless proved useful in analysing women's participation in motorised sub-cultures (Lumsden 2010).

Numerous studies of 'boy-racers' have emanated from Willis' (1978) study of 'motor-bike boys', which highlighted a sub-culture in which working class young men attained status through the material culture of their motorcycles and their performative skill and risk-taking with those bikes. Within these cohorts, dominated both quantitatively and symbolically by men, 'The touchstones of this world were manliness, toughness and directness of personal contact' (Willis 1978: 13). This resulted in a culture which was 'aggressively masculine', subordinated women, dehumanised ethnic 
minorities and was disdainful of mainstream society, its norms and social hierarchies. The immediate experiential world was privileged and premature death through challenging the boundaries of rider skill and machine was valorised over the mundane everyday life: ' [...] after the boundaries of skill had been passed, when the rider could do nothing more to save himself. That was 'the way to go': at the point of maximum exertion and skill' (Willis 1978: 17). More recent studies of 'boy-racer' car cultures (e.g. Falconer and Kingham 2007; Hatton 2007; Lumsden 2010) have shown the persistence of these traits. Car meets represent an opportunity for the 'staging of an appropriate masculine image' as well as expressing status, power and control in the context of unemployment or the lack of traditional 'masculine' employment (Hatton 2007: 217). The vehicles are a resource for establishing status and power in dynamic and volatile hierarchies (Falconer and Kingham 2007). Thus the intrinsic pleasure experienced through fast driving can be identified as 'risk compensation' for an otherwise mundane life (ibid.), risk being offset by perceived individual skill, and the preference for immediate experience and status over safety. Social changes and women's greater access to economic resources has resulted in some women participating in male-dominated car-cultures as drivers/ racers, rather than peripheral subordinated members of the scene (Falconer and Kingham 2007; Hatton 2007; Lumsden 2010). Women's successes are based on conforming to established masculine norms and evidencing vehicle-related skill and knowledge, and while this may result in the designation of 'Top Chick' (Falconer and Kingham 2007), ' their status can be undermined through sexualisation or dismissal as unfeminine. This results in 'girl-racers' deploying complex negotiations of compliant, resistant and cooperative femininities, e.g. complying with the cultural requirement for detailed knowledge of car-modification specifications combined with expressions of 'feminine' resistance such as pink livery (Hatton 2007; Lumsden 2010).

These studies provide useful insight to the mechanisms of gendered values and performances, with particular reference to technical knowledge and skill, as well as attitudes to speed and risk. It is to the question of risk and its intersection with motorcycling that we now turn.

\section{Risk and motorcycling}

Part of the allure of motorcycling is its association with risk-taking and the fantasy of adventure (Disko 2010), but risk-taking is predicated on uncertain cost-benefits and outcomes (Trimpop 1994: 9). Individuals' ability to identify risk is often inaccurate, risk-takers regularly underestimating risks (Yates and Stone 1992). Risk-taking is a persistent attribute of masculinity per se (Coles 2009), with various studies showing men tend to take greater risks than women, such as driving more dangerously and risky sexual practices (Courtney 1998). Women only tend to be more risk-optimistic when significant potential gains are combined with fixed minor costs (Harris et al 2006). More 
specifically, gender is one of the key risk factors in motor cycle riding (Sexton et al 2004), which is itself an inherently risky activity compared to car driving: motorcyclists are 46 times more likely to suffer a serious accident or be killed per kilometre travelled compared to car drivers (UK Department of Transport 2009; Pinch and Reimer 2012).

Indicators of risk include age, gender, experience, type of road, the nature and mechanical state of the motorcycle and driving conditions; hence, a 22 year old rider with 6 years' experience has a 50 per cent lower crash risk than a 17 year old rider with one year of experience (Sexton, Baughan, Elliot \& Maycock 2004, quoted in ROSA, 2011: 2). Attitudes to risk amongst motorcyclists have been classified into three groups by Sexton et al (2006), with 'Realistic Acceptors' being two to three times higher in the accuracy of their perception of risk than 'Risk Deniers' and 'Optimistic Acceptors'. While only 4 per cent of riders were unwilling to accept the objective risks presented to them for motorcycling per se, with the remaining 96 per cent agreeing that it was an acceptable risky activity, only 29 per cent worried about the risk (Sexton et al 2006: 19). While there is a correlation between riders who accept "more risk", with riding fast, getting more pleasure from riding and making more errors, in broader terms 'Virtually all agreed that you had to accept some risk otherwise life would be too boring' (Sexton et al 2006: 10). This suggests that motorcyclists tend to adopt a lifestyle values-based reflexive attitude to risk, however, 42 per cent of riders believed that the statistical risk to riders in their age category did not apply to them because of their ability as a rider, this being especially the case for older riders. In fact, most riders overestimate the objective risk faced by riders in their age category, but underestimate the risks faced by themselves as individuals (ibid.).

It has been suggested that those engaged in voluntary risky behaviour, are sensation-seeking rather than risk-seeking per se (Zuckerman 1994; also see Burke et al 2010). Factors that predispose individuals to engage in sensation-seeking or risk-taking activity include their genetic makeup and sociological factors (Zuckerman 1994). 'High sensation seekers' are willing to confront high risks to achieve their thrills, while 'low sensation seekers' do not consider the thrill as worthy of the risk. This reinforces Sexton et al's (2006) argument, which suggests a link between the acceptance of risk and the pleasure afforded by riskier motorcycle riding strategies. However, risk-taking choices are also dependent upon the motivational and emotional states of the individual at any one time, so that individuals could move from one category to another in accordance with their immediate circumstances and emotions. It is in this context that the notion of 'risk culture' is useful to this study. Lash (2000) uses the idea of risk culture (as opposed to risk society) to explain the role of the wider cultural context in risk evaluation, arguing that many such evaluations are based less on objective determinate judgement (e.g. statistical inference) than on aesthetic reflexive judgements, 
which incorporate 'affective, embodied and habitual notions of taste' as well as mental reflective evaluations. He argues, 'reflexive judgement is at the heart of risk culture' (Lash 2000: 52); in other words, values rather than prescribed rules (or statistical evaluations) underlie those judgements, and cultural contexts, such as the norms of a particular place or event, can influence that judgement..

This concept of risk culture is of particular relevance when considering both the mobilities of motorcycling as a sub-culture and the particular place-temporality of the assemblage of place/ events/values /performances which make up the cultural festival of the TT races as the setting for particular gendered performances. The significance of spaces of meets or events has been relatively neglected in studies of motorised subcultures (Falconer and Kingham 2007; Hatton 2007). As Leyshon and Brace (2007: 168) note, '[s]patialising the performance of masculinity is complex and occurs not within the terms of discrete cultural imaginaries, but in and through the fluid connections that people learn/have with space [and place]'. Both mobilities and gender are complex, contested and power-related and, furthermore, intersect in different ways according to the context of time, place and culture (Cresswell \& Uteng 2008). The consequence of this is that 'more work is needed to understand the gendering of motorcycle mobilities' (Reimer \& Pinch 2012: 10). As the competitors' performances represent the ideals of speed and skill at the TT races, in the next section we briefly analyse their self-and media-representation as a referential frame for discussion of spectator attitudes, aspirations and practices.

\section{TT competitors' attitudes to risk at the TT races}

'Why do they decide to race between stone walls at 190mph instead of on nice smooth, safe, purpose-built race tracks? Is there something wrong with them?' (Road Race Magazine 2010, 9).

The TT races are highly regulated. Racers themselves are evaluated by a medical officer and their machines undergo technical scrutiny. There are over $\mathbf{4 0 0}$ marshals on duty for each practice and race, the course itself is continuously evaluated in light of weather conditions and other factors, and safety and crash barriers are installed where possible to maximise protection for racers and spectators. Likewise, the Isle of Man Department of Economic Development (IOM DED) and Infrastructure and the police force work closely together to manage both the event and the large numbers of motorcyclists visiting the island, with a view to minimising risk to visitors and residents (Interview Michael Doherty, IOMDED, 2010). This is operationalized through mass safety awareness campaigns (see Figure 1 for the 2011 poster campaign), prohibited viewing spots, safety signs in key 
foreign languages, mobile speed cameras operated in speed-restricted residential areas and, since 2007, a one-way system enforced on the mountain section of the course for the full duration of the festival.

\section{[Insert Figure 1 about here]}

Nonetheless, risks remain for both racers and spectators. Over the more than 100 year history of the TT and associated Manx Grand Prix races, 227 riders have been killed racing the course (Corlett, 2010). This averages two racers per year, with further casualties to spectators, track marshals and others killed or injured while on other parts of the island during the festival. Recent open road statistics for TT accidents peaked in 2007, with 116 accidents and one fatality, reflecting the higher than usual spectator numbers attending the centenary TT. Most racers acknowledge the threat of death on the course. The late Dave Jeffries articulated the blending of skilled-ease and realism that Willis (1978) identified as representing the apogee of motorcycle riding: '[t]o succeed on the island, you have to be totally at ease with yourself and know exactly what you're doing, and accept that you might be going home in a box' (Fern, 2003: 1). As with 'boy-racers' (Hatton 2007), most TT competitors rely upon suspending the belief that it could happen to them. Ryan Farquhar exemplifies nuanced negotiation of Sexton et al's (2006) personal risk denial in the face of TT competitors' deaths: 'It is sad but they were like me - they knew the risks but thought it was never going to happen to them. I believe it'll not happen to me but I might be next, you never know' (Road Race Magazine 2010: 13).

The very challenge of road-racing is itself an attraction for many riders. Guy Martin, a competitor who, for many, epitomises a certain TT ideal of 'authentic' road-racing masculinity, explained that he preferred road-racing to short track racing:

'Because if you get it wrong it's gonna kill you ... but that's what I like about it. If it was safe I wouldn't do it. It's that simple' (Martin, 2010)

The attrition rate for competitors does not come near to the one in thirty fatalities experienced by those attempting to summit Mount Everest (see Burke et al 2010), but the margin between success and life-threatening failure is miniscule. However, Varley et al (1992), argued that the casualty rate for competitors of one per 113,000 kms between 1989 and 1991 on the TT course compared favourably with other motor sports. While short circuit racing is deemed less risky, all motorcycle racing is high risk. For example, twenty six times $\Pi \pi$ race winner Joey Dunlop (known as 'King of the [TT] Mountain' ) was killed during a short circuit race in Estonia in 2000, and lan Hutchinson, record- 
breaking winner of all five TT races in 2010, subsequently had an accident at the British Supersport Championship which threatened amputation of his left foot.

The perceived masculine prowess associated with the skill and risk-taking at the TT races is commonly represented discursively as 'having the balls'; Moto Grand Prix rider, Valentino Rossi, said of Guy Martin: 'Every time I see him I take my hat off to him because he has big balls to go so fast at the TT' (Rossi, 2009; also see Watterson 2010). This illustrates how the risks to the riders at the TT are perceived as extreme by some short circuit riders, who themselves would, in other contexts, be considered as extreme risk takers. For proponents of the TT such as Farquhar, the 'authentic' masculine TT environment is part of its attraction:

'... 'In road racing everybody seems more down to earth. The teams in British Super Bikes (BSB) paddocks are full of guys that are all hairdos and sunglasses whereas road racing's not really like that ...' (Road Race Magazine, 2010, 11).

While the UK Broadsheet news papers tend to be highly critical of the risks inherent to racing the TT, e.g. the headline: 'How many more will have to die?' (Wooldridge 2003),Motorcycle magazines and televised coverage tend to valorise the skill and courage required to face those same risks. One television commentator underscored the risk-accepting ideal, describing road racing as '[n]to the line of work to be in if you're worried about that [crashing] ... you might as well do extreme crocheting' (ITV4 3/6/12), thereby articulating an ideal of fearless masculinity while discursively emasculating any competitor expressing such worries. However, this representation of TT competitors as a single uncomplicated 'ideal -type' masculinity contrasts with many competitors' frank acknowledgment of fear, the knife-edge on which their lives rest, and sadness at colleagues' deaths. John McGuiness, nineteen times $\Pi T$ winner, described himself as being petrified before races, highly mortalityconscious and superstitious, never racing without his lucky charm (McGuiness, 2012). Similarly, the Island Racer article 'nice guys finish first', representation of TT record holder lan Hutchinson, cuts through simplistic stereotypical images of alpha-male TT winners (Moss 2010, 108). These examples illustrate the complex masculinities and embodied emotional sphere inhabited within the elite cohort of top TT racers, let alone the 30,000 plus body of annual spectators. Indeed, as Moffat $(2012: 3,8)$ notes:

'Any epistemological exercise that attempts to define a sole expression of what it is to be male is challenged through local practice ... essentialist definitions of masculinity and unitary forms of masculine practice are not relevant to lived experience'. 
The presence of female TT competitors, such as women's TT lap record holder Jenny Tinmouth (average lap speed of $119.95 \mathrm{mph}$ ), also challenges simplistic constructions of risk-taking as the preserve of masculinity. Women's participation may depend upon what is perceived as 'masculine performances' but demonstrates that some women can deliver the required knowledge, skill and risk-taking (Falconer and Kingham 2007; Keng 2005; Mannering and Gradsky 1995; Quddus et al 2002). When asked what kind of woman it takes to line up against an entire field of "'testosteronefuelled men" in "the toughest road race in the world"' (Barker 2010: 91), Tinmouth outlined how she negotiated attitudinal challenges as well as those of the race itself:

'The TT is obviously quite a big risk but it's one of those things that you've just got to do. For a bike racer it's the ultimate ... No one takes you seriously when you're a female racer. No one thinks you're any good until you go out and prove it. You're basically written off before you've even started. But that suits me fine because I like to be under the radar; it makes it more satisfying when you get a good result' (Barker 2010: 93-96).

Tinmouth's slow crash during practices in 2010 prompted an immediate post on Nothwestbikers.net questioning whether women should be allowed to race the TT. This prompted a flurry of responses praising her skill and courage in terms of ideal-type masculinity e.g. 'Give the girl credit mate, shes [sic.] having a go at the most dangerous track in the world. Should women race bikes....Yes, coz the rules say so and any girl that has the BOLLOCKS to do the TT has my admiration 1000\%' (Nothwestbikers.net 2010). However, the original post is indicative of some men's desire to belittle women's successes as competitors and to marginalise women as subordinate within the masculine arena of the TT.

Popular valorisation of testosterone-fuelled fearlessness in TT media coverage and advertisement campaigns by sponsors, echoes discursive themes in UK 'lad's magazines' such as Zoo and Nuts which represent high-risk sport as an ideal expression of masculinity (Jordan and Fleming 2008). Despite these popular discourses, TT racers are far from fearless, but, like many high-level extreme sports competitors, practice varying degrees of optimisitic acceptance of risk and view fear as a potentially useful emotion that can keep them safe (see Le Breton 2000). However, spectators are exposed to relentless advertising campaigns and commentaries which reiterate the discourse of TT competitors' heroic masculinity with places in the TT hierarchy established through lap and win records (required and TT 'knowledge'), which culminates in the top racer being declared 'King of the Mountain'. These pervasive values, exemplified by the $2011 \mathrm{t}$-shirt celebrating racers who 
experienced life-threatening crashes in 2010 (see Figure 2 ) frames spectators' appreciation of the races, and their evaluation of their own an others' performances at the event.

\section{[Insert Figure 2]}

Figure 22011 T-shirt with heroic representations of Connor Cummins and Guy Martin, survivors of major crashes in 2010.

In the case of the TT festival, Crowther (2007: 2) argues that not only does the journey to the island provide opportunities for 'self- formation', but that 'Engaged in a bodily escape, motorcycling visitors take time out to enjoy leisure, a release from chronological time and a retreat from a world both spatially and temporally'. This implies that the setting alters the individual's normal ways of perceiving the world, either through the lens of the TT's traditions and/or through feelings and attitudes shared with one's travelling companions which conceivably contribute to TT-grounded 'group-think' attitudes to risk. Helms (1984) refers to this group dynamic as 'risky shift behaviour' where, in some circumstances, individuals will take risks within a group that they would be unwilling to take on their own. Given that nearly 80 per cent of those attending the TT races are men, gender and constructs of masculinity are key to evaluating attitudes to risk and speed at the festival.

\section{Perceptions and Experiences of watching the TT races}

The first thing to note is that all spectators are travellers. With the exception in this case of residents who literally live on the circuit, all TT spectators have undertaken an elective purposive journey to attend the races. TT spectators are neither passive nor static. The majority of visiting spectators have journeyed across the Irish Sea, whilst international visitors (13 per cent of the sample, including those from Belgium, Italy, the United States, Australia and New Zealand) undertake medium to long-haul journeys, including those who have ridden across mainland Europe and the UK before reaching the ferry. The TT races attract a tremendously loyal core of supporters, and 68 per cent of respondents had attended previously, roughly equivalent to the 71.5 per cent reported by the loM TT exit Survey (2010), with as many as Sixty-four per cent visiting each year (IoM Government 2010). Impressive records of longevity of attendance represent embedded annual practices of family mobilities centred on the TT; for example, '[e]very year since I was born [46th year]' (123, Visitor, Male, 45-59 years), prompting obvious parallels with pilgrimage (Gale et al 2014). 
The nature of the TT course itself makes access to multiple viewing points possible, with spectators choosing different vantage points on the course according to the race, weather and post-race plans; some also ride between locations during the race. Central to the following discussion, spectators with vehicles have the opportunity of riding the public roads which make up the course. One spectator stressed these dynamic and interactive practices:

[There is] A totally different atmosphere [at the TT compared to other races]; you watch the race then ride your bike. Down at the Grand Prix you're parked up for the weekend' (130, Visitor, Male, 18-19 years).

In addition to this physical travel undertaken by spectators, Manx Radio TT race coverage also provides a means of virtual imaginative 'travel' with the race leaders through its commentary points from around the course. This keeps spectators who are located in a particular place, apprised of the race's progress and key events. This commentary is particularly important in a staggered-start time trial race taking place over a 38 mile course and allows imaginative visualisation of and virtual 'presence' of spectators at the race-elsewhere. Televised highlights (which include on-bike cameras, aerial helicopter footage and fixed point film) allow a global audience to view the race highlights, with helmet and on-bike cameras providing audiences with a perspective that simulates actual participation.

When asked what attracted them to the $\pi$ races, 58 per cent identified race/course-related attractions, including the speed and skill of the racers and the opportunity for spectators to ride the course themselves. Other reasons included the social aspects of the whole experience, such as the wider TT festival (15 per cent), and being with friends and family (14 per cent) and the island itself ( 9 per cent). A sense of this assemblage which constitutes the attraction of the TT festival is exemplified in the following quotes by visitors and residents:

'risk and danger, hospitality of the Manx, scenery of the Island, atmosphere of crowd (and Manx Radio!)' (73, V, F, 20-29)

'The speed and closeness of the bikes' (1, $R, M, 45-59)$

For these respondents the multiple and intersecting motivations and experiences cannot be separated; speed and risk are inherent to the event, but so are the local people, landscape and sense of communality in the crowd. While spectators' word association responses (see figures 2 and 3 ) linked the TT festival principally with 'beer', 'speed', 'fun' and 'excitement', they were closely followed by 'bike community' and 'friendly locals'. This suggests speed and excitement were privileged over risk per se (echoing Lumsden 2010). It also highlights the significance of permanent 
attributes such as 'friendly locals', as well as the supporting programme of social events alongside the races. This also illustrates the dynamic mobility of place identity and practices that occur on the Isle of Man during the TT festival, including a 40 per cent increase in the population; transformations akin to those experienced by cities hosting larger scale mega-events such as the Olympics (see Roche 2000; Sheller and Urry 2004).

\section{Figure 3 Example of TT experience word association sheet}

\section{[insert figure 3 ]}

One international visitor in his forties focussed his word association responses on speed, thrill and people (fellow bikers and locals), while explicitly dismissing non-TT-related attractions by crossing out the whole box with words associated with landscape, wildlife, heritage and so on (see Figure 3). Another visitor in his thirties circled 'open road', 'mates', 'beer', 'museums' and 'trains', suggesting a meshing of interests indicative of a different sort of self-reflexive masculinity with a wider interest in transport/engines and heritage, mechanical knowledge as well as driving skill being a sign of masculine capability (Lumsden 2010). These complex intersections could also be seen in the respondent who chose his viewing spot on the basis of danger, 'Bottom of Bagarrow - dangerous and exciting' (15, Visitor, Male, 45-59 years), but also visits the Manx Cat Sanctuary to see the 'cute pussy cats', thereby exemplifying Lawler's (2008:3) notion of 'varying and contradictory identities', as well as challenging simplistic typologies of masculinity. This can also be seen in the 'Nearly Naked Man' $T$ ride out to raise awareness of prostate cancer. Here the masculine cultural space and captive audience of the TT festival is used as a space of intervention to raise awareness of the disease, with a combination of factual advertisement campaigns, humorous bravado and acts of memorialisation being deployed to communicate the health message.

Despite these nuances, speed and risk, attributes associated with hegemonic sporting masculinities, are nonetheless central to the ethos of the TT races. This is exemplified by the film TT3D Closer to the Edge, with the telling strap line: 'Just because you're breathing, doesn't mean you're alive'. Speed, risk and associated adrenalin also featured in spectators' most memorable experiences. For 93 per cent of respondents, their most memorable experience of the TT couldn't be replicated elsewhere and was often was related to speed:

'... first visit when I couldn't believe the speed' (113, Visitor, Male, 30-44 years) 
'Watching John McGuiness go through the Grandstand at 183mph. AWESOME. (2007)' (142, Visitor, Female, 45-59 years)

Speed was also a factor determining spectators' preferences for where to view the course. Seventyseven per cent of respondents expressed a preference for viewing spots on the TT course, the most popular being: The Gooseneck (14 per cent) and Creg-ny-Baa (11 per cent). The most important factors affecting choice of viewing spot are: proximity to and view of the race action (58 per cent); access (13 per cent); facilities (10 per cent); and the weather (7 per cent).

Proximity to the course was a key spectator motivation; this allowed full appreciation of the skill and thrill of the race (notably at corners rather than faster straight sections of the course):

'... areas that are accessible and show skill and nerve' (54, Visitor, Male, 45-59 years)

'To find a spot that has the best action and scary factor' (55, Visitor, Female, 45-59 years) A minority of respondents were influenced by their concerns for their own and racers' safety, for example:

'safety travelling to viewing point' (100, Resident, Male, 60-74 years)

'somewhere relatively safe - [I] do not want to see anyone hurt ...' (22, Visitor, Female, 45-59 years).

These comments suggest that some spectators mobilise strategies for managing and minimising personal risk, both physical and emotional. However only 2 per cent of respondents indicated that 'too many' TT-related accidents or fatalities would deter them from attending the races:

'... possibly if I saw a fatal' (117, Visitor, Male, $30-44$ years)

'[If] too many racers killed' (93, Resident, Male, 30-44 years).

Several spectators identified crashes they had seen or experienced as among their most memorable TT experiences:

'Yesterday's Senior race red flagged due to Guy Martin's accident will stay with me for some time' (73, Visitor, Female, 20-29 years)

'Unfortunately coming off at a very low speed on a newly overbanded road' (162, Visitor, Male, 60-74 years).

However, one respondent noted a strategic selective memory in response to these risks: 
'... I don't dwell on the bad things ...' (132, Visitor, Male, 60-74 years).

This suggests a large degree of either denial or optimistic acceptance in relation to the risks undertaken by racers and to a lesser degree by the spectators themselves. Indeed, 15 per cent of respondents identified increased regulation of spectators' access to the course as likely to put them off attending the races. Male and female residents and visitors complained:

'too many restrictions on viewing $-H \& S$ [health and safety] culture, overzealous marshals (will 'kill the race' if they carry on as they are ...). ' (81, Visitor, Male, 45-59 years).

The pivotal aspect of spectator attitudes to risk is a shared sense of risk generated by the culture which surrounds the $\mathrm{TT}$, namely that the spectators respect the risks taken by the racers and want to be allowed to judge their own risks associated with their active participation in the festival, especially when choosing where to view the race. As one female visitor explained:

'When I started coming, you could watch anywhere. Health and Safety has gone madpeople know the risks ...' (135, Visitor, Female, 45-59 years).

\section{Spectator experiences of motorcycle riding at the $\pi$}

Public participation in riding the circuit represent a near-unique mobility for motorsport spectators, allowing motorcyclists to participate in their own form of embodied extreme sport through emulating their race heroes. This is the defining moment of the TT experience for some respondents:

'[Riding] fast over the mountain one way ...' (116, V, M, 60-74).

'Riding Glen Helen [section of the course] and getting it just right ...' (139, V, M, 60-74).

For the latter respondent, his satisfaction was in the embodied-emotional experience of perfecting his own moto-mobility skill at one single time-place - not watching a professional racer do the same thing. This reflects Crowther's (2007: 2) assertion that '[t]he quest for sensual velocity on the Mountain Course is an essential ingredient of motorcycle travel experience at the TT as the visitors to the Isle of Man come to know the place through their motorcycles and bodies'. This echoes the 'accelerated sublime' experience of other extreme sports enthusiasts such as bungee jumpers or white water rafters, which Bell and Lyall (2002: 22) have described as like 'adventure heroes starring in their own movies'. This perception is literally facilitated at the TT by photographers who capture images of amateur motorcyclists on the mountain road during the festival, allowing riders to view and purchase pictures of themselves riding the TT circuit. The use of helmet cameras underscores 
the performance of many TT spectators who use technology to capture, record and share their personal embodied-emotional, moto-mobility participation in the TT and reflects the importance of audiencing for many extreme sport performers (see Falconer and Kingham 2007).

However, is the phenomenological experience of spectators riding the TT course universal and is this inflected by differentiated attitudes to risk? In response to a direct question on motorcycle riding during the TT festival, 31 per cent reported riding their bike faster during the TT period. In terms of gendered attitudes to risk, it is significant that this cohort was made up entirely of male visitors, and included 12 per cent of international survey respondents, suggesting that these men conform to the categories of 'Risk Deniers' or 'Optimistic Risk Acceptors'. However, there was considerable variation within this group. Some referred simply to the legal opportunity to ride a little faster on the Island than elsewhere, others to optimising their participation in the event by riding the course, and others to the opportunity to ride their machines to their full capacity:

'Faster ... because I can' (136, Visitor, Male, 60-74 years)

'... yes, I can use the bike as intended over mountain' (3, Visitor, Male, 30-44 years)

'Go fast over the mountain as many times as possible' (116, Visitor, Male, 60-74 years)

While this confirms the correlation between speed, risk-taking and masculinity, and is suggestive of riskier riding within the context of the place-temporality and speed-valorising culture of the TT races, in contrast to studies of 'boy-racers' which have linked risky riding with youthful working class masculinities, these men were in fact drawn from a variety of age ranges and a range of occupations including a scientist, a pest controller, an accountant, a product manager, a police officer and a retired pensioner. This compels any analysis of pleasure in speed as more than a response to youthful social-economic disempowerment.

The response of one visitor exemplifies a context-sensitive and enhanced-risk taking approach while immersed in the place-time context of the speed culture of the TT races:

'Faster. Willing to take more risk than back home....' (121, International Visitor, Male, 30-44 years).

It is argued that being a tourist is to occupy a liminal role with 'a temporary marginality' (Ryan and Hall 2001: 1), whereby . tourists free from everyday obligations can 'leap' as if off a springboard (Jafari 1987), be temporarily immersed in the tourist world, then return back to everyday life and practices (Bowen and Clarke 2009). The responses above suggest that for these spectators, being set 
apart on the island with its different speed laws and the wider motorcycle festival, represents a liminal space in which they can behave differently, including riding faster and taking greater risks.

While no respondents referred to peer pressure to ride fast, one international visitor felt compelled to ride faster than he would have wished, as a safety strategy, due to the ambient speed of other motorcyclists: 'Yes [faster], reluctantly, if you ride very slow you feel like an obstacle, its more dangerous to ride very slow so I ride faster' (169, International Visitor, Male, 20-29 years). Nonetheless a number of respondents indicated that the opportunity for spectators to ride round the course on 'Mad Sunday' was a mandatory part of the experience of visiting the TT races, especially for first timers, suggesting a degree of group-think: 'To be part of it, to be able to say l'd completed the course on Mad Sunday' (11, Visitor, Male, 46-55 years); 'Visiting from Australia we believe it is the traditional thing to do' (36, International Visitor, Male, $46-55$ years).

However, of the 31 per cent who reported riding faster than usual while at the TT festival, the majority rationalised that their increased speed was within both the Island's legal speed limits and their own capabilities:

'I ride fast on the mountain and through unrestricted areas but obey all [speed] limits, we're allowed to go flat out elsewhere so why speed in villages?' (16, Visitor, Male, 30-44 years)

Despite being surrounded by over 10,000 other motorcyclists on rural roads, one respondent rationalised that the risks were less than at those of fast traffic-heavy roads in the UK (Dartford, Kent):

'Traffic at home requires more attention to personal safety' (44, Visitor, Male, 45-59 years).

Some respondents chose not to ride their motorcycles at all during the TT period:

'I would never ride on loM during TT fortnight. Too many crazies' (167, International Visitor, Male, 60-74 years)

and a further fifteen per cent of respondents reported riding their motorbikes more slowly/carefully during the TT festival, including residents.

'More carefully here due to volume of traffic and other road users' (152, Visitor, Female, 3044 years)

'Take a lot more care/ride slowly - more bikers and potential for accidents' (83, Resident, Male, 45-59 years) 
'I ride even more vigilantly as there is more need for 'life savers' before changing lanes due to other bikes' (157, Visitor, Male, 20-29 years)

This group also included a range of ages and occupations: a salesperson, a retired analytical chemist, two engineers, a ski instructor, a computer software consultant and a university student. Notably, this group included women, indicating that female motorcyclists, although a relatively small cohort within the total motorcycle riding spectators at the TT festival (c. 5 per cent), are more likely to ride the same or more slowly than their male counterparts. One female motorcyclist attributed her safety to a lack of gendered competitiveness on the road, but also took extra personal care and limited her geographical range in order to minimise perceived risks:

'Yes! Some bikers go to the Island - see the 'NO LIMIT' [to the national speed limit] and go mad. Therefore I stay off the Mountain section during TT week. Perhaps, being a female biker, I don't get drawn into that 'boy racer'/male top dog/attitude! I ride even more defensively when on Island ....' (142, V, F 45-59).

Her comments suggest that it is harder for men to sidestep 'boy-racer' competitiveness. However, the majority of bike riders (54 per cent) reported no difference in how they ride their motorcycles when at the TT festival.

\section{Conclusion}

TT race spectators are predominantly male and the proximity to speed is central to their enjoyment of the TT races. However, spectator demographics and the total TT experience are more complex than those invoked by images of 'boy racers'. The attractions of the thrills of the race intersect with social, emotional, physical and aesthetic experiences within the local and visiting motorcyclist communities, as well as the unique TT-related mobilities experienced by spectators. The majority of spectators valorised speed and skill, but deployed optimistic-acceptance or risk denial in order to frame the race in terms of thrill and excitement rather than danger. Some of those spectators who explicitly recognised the risks undertaken by competitors showed this through badges and clothing which featured skeletons and other memento mori and participated in that risk-culture themselves by riding the course on Mad Sunday or in choosing riskier (increasingly prohibited) places to watch the races. While some of the men comprising the 31 per cent of motorcycling respondents who reported riding their bikes faster at the TT festival, were driven principally by a desire to experience their bikes at full-capacity and/or to emulate the competitors on the race circuit, half of this group stressed that they respected speed limits where they applied, i.e. operated within legal frameworks. Over two thirds of motorcycle-riding TT spectators reported riding their bikes at the same speed as 
or more slowly compared to other time-spaces. Thus despite the place-temporality of the TT races and its wider cultural field of speed, risk and competitiveness, only a minority of motorcyclist spectators practiced deliberate increased risk-taking. However, Sexton et al's (2006) study suggests that while this minority group may get more pleasure from riding fast, they are most vulnerable to making mistakes. Within the context of a competitive hierarchical environment which valorises risktaking and skill as an ideal-type of masculinity and implicitly encourages comparative performances by some spectators, risk-deniers and optimistic-acceptors are tempted to ride beyond their skill in order to gain status through performative risk-taking and/or higher thresholds of norms of speed emanating from the group-think of the TT race festival. That performance could be measured in terms of speed, or also captured by helmet-cams or professional still photographs of spectatorbikers as they ride the circuit, materialising the fantasy of TT experience in visual media, an ultimate souvenir which can be shared with others as both proof of and metonym for skill and experience.

The TT festival is a predominantly homo-social but heterosexual space, with a high proportion of men spending time largely in the company of other men and an ideal femininity exemplified by sponsors' 'podium girls'. However, despite the macho and 'tearaway' image popularly attributed to motorbike riders, which might be associated with hegemonic and complicit masculinities, the largely middle age and middle class cohort in this study reflects the wider demographics of motorcyclists in the British Isles and represented a variety of performative mobilities and multiple dominant masculinities at The TT festival, including sensation-seeking risk-takers and prudent risk-minimisers. While female spectators were just as likely to seek the thrill of proximity to the circuit as their male counterparts, no women motorcyclists in this survey rode at greater speed during the festival. While female motorcyclists are taking greater risks relative to driving a car, thereby challenging gender assumptions about risk, they have a low tolerance for personal risk-taking and privilege selfpreservation over thrill-seeking riding. This echoes other studies of gender and risk which identify complex negotiations of compliant and resistant femininities on the part of 'girl-racers'. Demographic analysis of those men willing to ride their motorcycles faster and those riding more carefully/slower than usual shows both cohorts are diverse groups, including different ages and different socio-economic occupational groups: both younger working class men taking greater care and older middle class men taking more risks than usual, while riding their motorcycles at the TT festival. While numerous studies of motorcyclist culture suggests inherent risk-taking, and the popular assumption of the TT races and their supporters might be of risk-taking young men, evidence from this detailed survey shows a more complex picture of the masculinities being practised by spectators at the TT races. 
This study attends to the specificity of spatial context for the performance of both mobilities and gender, with particular attention to masculinities. It exemplifies a particular inter-relation of mobilities and place identity, including in this case the notion of 'islandness', whereby the geographical location and independent legislation accommodates an extreme sport and a wider motor-cycle-focused cultural event, facilitates a sense of alterity and normalises a culture of speed and risk. In addition to underscoring the conceptual and methodological importance of situated research of mobiliities in specific place-temporalities, this study brings to light the highly significant and under-researched embodied, performative and emotional mobilities of spectators, a topic which merits more attention from mobilities scholars. It also demonstrates the importance of wider surveys of motorcyclist communities to complement small cohort ethnographic studies which have shaped much of existing analysis. 


\section{References}

Barker, S. 2010. Jenny Tinmouth. First Lady. The Official TT Programme. Douglas: Isle of Man Government.

Bell, C. and Lyall, J. 2002. The Accelerated Sublime: Landscape, Tourism and Identity. USA: Greenwood Praeger.

Berg, L. and Longhurst, R. 2003. Placing masculinities and geography. Gender, Place and Culture, 10 (4), 351-360.

Bowen D and Clarke J 2009 'Contemporary tourist behaviour: yourself and others as tourists.', CABI Publishing: Wallingford

Burke, S.M., Durand-Buch, N. and Doell, K. 2010. Exploring feel and motivation with recreational and elite Mt Everest climbers: an ethnographic study. International Journal of Sport and Exercise Psychology, 8 (4), 373-393.

Butler J. 1990. Gender Trouble. Feminism and the subversion of identity. London: Routledge.

Byrnes, J. P., Miller, D. C., \& Schafer, W. D. 1999. Gender differences in risk taking: a meta-analysis. Psychological Bulletin, 125, 367-383

Coles, T. 2009. Negotiating the field of masculinity. The production and reproduction of multiple dominant masculinities. Men and Masculinities, 12 (1), 30-44.

Connell, R. W. 1987 Gender and Power: Society, the Person, and Sexual Politics. Stanford: Stanford University Press.

Connell, R. W. 1995 Masculinities. Berkeley: University of California Press.

Cooper, C. and Jackson, S. 1989 Destination life cycle: the Isle of Man case study. Annals of Tourism Research, 16 (3), 377-383. 
Corlett, A. 2010 Why you should watch...Isle of Man TT. Available at:

http://www.f1fanatic.co.uk/2010/06/04/why-you-should-watch per centE2 per cent80 per centA6isle-of-man-tt/ Accessed 9 ${ }^{\text {th }}$ August 2010.

Cresswell, T. and Uteng T.P. 2008. Introduction. Gendered Mobilities: towards an holistic understanding. In. T.P. Uteng and T. Cresswell, eds. Gendered Mobilities. Aldershot: Ashgate, 1-6

Cresswell, T. and Merriman P. 2011. Introduction. Geographies of Mobilities. Practices, spaces, subjects. In. T. Cresswell and P. Merriman, eds . Geographies of Mobilities. Farnham: Ashgate, 1-18.

Crowther, G. 2007. Embodied Experiences of Motorcycling at the Isle of Man TT Races [online]. International Journal of Motorcycle Studies, Special TT Centenary Edition. Available from: http://iims.nova.edu/November2007TT/IJMS Artcl.Crowther.html [Accessed 10th August 2010].

De Aragues, R. (Director) 2011 TT 3D. Closer to the Edge, (DVD), CinemaNX, Douglas.

Department of Transport. 2009. Transport Statistics Bulletin: Compendium of Motorcycle Statistics. Available at:

http://www.dft.gov.uk/adobepdf/162469/221412/221552/228173/517838/motorcyclingstats2009. pdf (Accessed 14 March2012).

Disko, S. 2007. The image of the 'Tourist Trophy' and British motorcycle racing in the Weimar Republic [online]. International Journal of Motorcycle Studies . Available at:

http://ijms.nova.edu/November2007TT/IJMS Artcl.Disko.html Accessed 15 th June 2010.

Economic Affairs Division, Isle of Man Treasury. 2011. TT Survey 2010. Douglas: Isle of Man Government

Evans, S. 2010 available at: http://www.simonevans.co.uk/v-four/tt.htp Accessed (th $^{\text {th }}$ August 2010.

Fern, D. 2003. Motorcycling: TT's fastest rider dies after $160 \mathrm{mph}$ accident. The Daily Telegraph, 30 May.

Gale, T., Maddrell A., and Terry, A. 2014 (forthcoming) Sacred Mobilities, Farnham: Ashgate. 
Hackney, R.G., Varley, G., Stevens, D. and Green, A. 1993. Trauma on the Isle of Man. British Journal of Sports Medicine, 27 (1), 9-13.

Hannam, K., Sheller M., and Urry J. 2006. Editorial. Mobiliities, immobilities and moorings, Mobilities, $1,1-22$.

Harris, C. R., Jenkins, M. and Glaser, D. (2006) Gender Differences in Risk Assessment: Why do Women Take Fewer Risks than Men? Judgment and Decision Making, Vol. 1, No. 1, 48-63

Hatton, Z. 2007. The Tarmac Cowboys: an ethnographic study of the cultural world of boy-racers, (Unpublished Ph.D. Thesis, University of Plymouth).

Helms, M. 1984. Factors affecting evaluations of risks and hazards in mountaineering. The Journal of Experiential Education, 7 (3), 22-24.

Hopkins, P.E. 2007. Responding to the 'crisis of masculinity': the perspectives of young Muslim men from Glasgow and Edinburgh, Scotland. Gender, Place and Culture, 16 (30), 299-312.

Hutch, R. 2007. Speed masters throttle up: space, time and the sacred journeys of recreational motorcyclists, International Journal of Motorcycle Studies, July. Available online at: http://ijms.nova.edu/index.html

Isle of Man Police 2008. TT fans rode outside of capabilities, say police, available at: http://www.iomtoday.co.im/news/isle-of-man-news/tt-fans-rode-outside-of-capabilities-say-police$\underline{1-1773513}$ Accessed $10^{\text {th }}$ August 2010

Isle of Man Today 2010. $T$ t boosts Manx economy by f19m. Available at: http://www.iomtoday.co.im/news/isle-of-man-news/isle-of-man-tt-boosts-manx-economy-by-16319m-report-1-1747869 Accessed $12^{\text {th }}$ July 2012.

Isle of Man Treasury, 2010. $T$ T Survey 2010. Douglas: Isle of Man Government 
Jordan, F. and Fleming, S. 2008. Nuts, Zoo, and the mediation of youthful masculinity, Leisure 32, 2, pp 331-351.

Keng, S.H. 2005. Helmet use and motorcycle fatalities in Taiwan. Accident Analysis and Prevention, 37(2) 349-55.

Lash, S. 2000. Risk Culture. In. B. Adam, U. Beck and J. Van Loon, eds. The Risk Society and Beyond. London: Sage, 47-62.

Lawler, S. 2008. Identity. Sociological perspectives. Cambridge: Polity

Le Breton, D. 2000. Playing symbolically with death in extreme sports. Body \& Society, 6 (1), 1-11.

Levy, D.P. 2007. Hegemonic Masculinity. In. G. Ritzer, ed. Encyclopaedia of Sociology, Blackwell (online version accessed July 2010).

Leyshon, M. and Brace, C. 2007. Men in the desert: Contested masculinities in Ice Cold in Alex. Gender, Place and Culture, 14 (2), 163-182.

Lumsden, K. 2010. Gemdered Performances in Male-Dominated Subculture: 'Girl-Racers', car modification and the quest for masculinity, Sociological Research Online, (15 (3) 6 (accessed 10/7/2013).

Mannering, F.L., Grodsky, L.L. 1995. Statistical analysis of motorcyclists' perceived accident risk, Accid Anal Prev. 27(1) 21-31.

Martin, G. 2010. The Madness of Guy Martin. Road Race Magazine, Issue 1, 66-71.

McGuiness, J. 2012 King of the Mountain, ITV4, June 2012.

Moffat, K. 2012. Introduction. In. K. Moffat, ed. Troubled Masculinities. Toronto: Toronto University Press, 3-20.

Moss, C. 2010a. Ian Hutchinson. Nice guys finish first, Island Racer, 108-112. 
Moss, C. 2010b. Road Racers. A breed apart. Road Race Magazine, 1, 8-13.

Nothwestbikers.net (2010) http://www.Nothwestbikers.net/ Watch Jenny crash ... (accessed 10/3/2012)

Quddus, M.A., Noland, R.B., and Chin, H.C. 2002. An analysis of motorcycle injury and vehicle damage severity using ordered probit models. Journal of Safety Research, 33(4), 445-462.

Rossi, V. 2009 Rossi TT update: "Guy Martin has big balls" Motorcycle News 29 at: $\underline{\text { http://www.motorcyclenews.com/MCN/News/newsresults/General-news/2009/April/apr2909- }}$ Rossi-TT-update-Guy-Martin-has-big-balls/ Accessed $10^{\text {th }}$ August 2010.

Pinch, P. and Reimer, S. 2012. Moto-mobilities: Geographies of the motorcycle and motorcyclists. Mobilities, 7 (3?), 1-19.

Roche, M. 2000. Mega events and modernity. Olympics and expos in the growth of global culture. London: Taylor Francis

ROSA 2011. European Handbook on Good Practices in Safety for Motorcyclists": ENFORCEMENTPOLICIES: available at:

http://ec.europa.eu/transport/road safety/pdf/projects/rosa handbook enforc en.pdf Accessed $14^{\text {th }}$ March 2013

Ryan C. and Hall M. 2001 Sex Tourism. Marginal people and liminalities, Routledge, London.

Sexton, B., Baughan, C., Elliott, M. and Maycock, G. 2004. The accident risk of motorcyclists, TRL Report, TRL607, Crowthorne: TRL.

Sexton, B., Hamilton, K., Baughan, C., Stradling, S. and Broughton, P. 2006. Risk and Motorcyclists in Scotland [online]. Scottish Executive Social Research, Edinburgh. Available at:

http://www.righttoride.co.uk/virtuallibrary/riskandmotorcycling/RiskandMotorcyclistsinScotland.pd f. [Accessed 18 August 2010]. 
Sheller, M. 2004. Demobilizing and remobilizing Caribbean paradise. In M. Sheller and J. Urry, eds. Tourism Mobilities. London: Routledge, 13-21.

Sheller, M. and Urry, J. 2004. Places to play, places in play. In. M. Sheller and J. Urry, eds. Tourism Mobilities. London: Routledge, 2-10.

Trimpop, R.M. 1994. The Psychology of Risk Taking Behaviour. Advances in Psychology, 107. Amsterdam: Elsevier Science.

Vannini, P., Taggart J. 2012. Doing islandness: a nonrepresentational approach to an island's sense of place, Cultural Geographies 20(2) 225-242.

Varley, G., Thomas, P.C., Spencer-Jones R. 1992. Injury patterns in Motorcycle Road Racers. Presentation to the British Orthopaedic Association Meeting, London UK, 9-11 September 1992.

Watterson, J. 2010. Survivors Moving Forward. Island Racer 70-76.

Willis, P. 1978. Profane Culture. London: Routledge and Kegan Paul.

Women and Geography Study Group (WGSG). 1997. Feminist geographies. Explorations in diversity and difference. London: Longman.

Wooldridge, I. 2003 How many more will have to die? Daily Mail 31/5/2003

Wunderlich, F.M. 2010. The aesthetics of place-temporality in everyday urban space: the case of Fitzroy Square. In. T.Edensor, ed. Geographies of Rhythm. Nature, Place, Mobiliites and Bodies. Farnham: Ashgate, 45-56.

Yates, J.F. and Stone, E.R. 1992. The risk construct. In. J.F. Yates, ed. Risk Taking Behaviour. New York: Wiley.

Zuckerman, M. 1994. Behavioral expressions and biosocial bases of sensation seeking. New York: Cambridge University Press. 